\title{
Menopause and the Asian Woman
}

\author{
Sumbul Sohail
}

\begin{abstract}
Menopause is an event that typically occurs in women in midlife. For some women, the accompanying symptoms can significantly disrupt their daily activities and sense of well being. It has long been known that menopause is much easier for Asian women than for westerners. A systematic review of articles on Asian women is done, the objective of which is to find out evidence on Asian women experience and perception of menopause.
\end{abstract}

Keywords: Menopause, Hot flushes, Asian, Lifestyle, Ethnic difference.

How to cite this article: Sohail S. Menopause and the Asian Woman. J South Asian Feder Menopause Soc 2014;2(1):23-25.

\section{Source of support: Nil}

Conflict of interest: None declared

\section{HOW ARE WE DIFFERENT?}

Menopause may be a universal biological phenomenon and the individual experience of women from different parts of the world is different. ${ }^{6}$ How a woman perceives and responds to the menopause is colored by her culture. This difference that we observe may have their origins in their different genetics, lifestyle and culture. Our management of menopause must therefore be guided by these differences.

Asian women welcome the phase in which she no longer has to bear this discomfort of menstruation. Asia has more than half of the world's population. It embraces many different cultures.

\section{THE ASIAN EXPERIENCE OF MENOPAUSE}

It is commonly believed that Asian have a lower prevalence of menopausal symptoms than Western women. ${ }^{1}$ A survey of some of the epidemiological studies conducted in different regions of Asia shows this to be generally true with a few exceptions. $^{2}$ A population-based study based in Singapore on 1,000 women aged 45 to 60 years noted that overall just $7 \%$ of the women were significantly bothered by any of the symptoms of menopause. ${ }^{9}$

General Secretary, Associate Professor

Pakistan Menopause Society; Department of Gynecology and Obstetrics, Karachi Medical and Dental College, Karachi Pakistan

Corresponding Author: Sumbul Sohail, General Secretary, Pakistan Menopause Society; Associate Professor, Department of Gynecology and Obstetrics, Karachi Medical and Dental College Karachi, Pakistan, e-mail: sumbul.sohail01@gmail.com
This is particularly true when we consider only classical vasomotor symptoms such as hot flushes but other studies conducted among Asian menopausal women demonstrate a prevalence of significant hot flushes from 10 to $30 \%{ }^{3,7,13}$

\section{CULTURAL VIEWS OF THE MENOPAUSE}

Culture is a subject which is difficult to understand in scientific terms. It is perceived in different ways by different people. ${ }^{5}$ However, culture should include not just the set of values but also particular diets and lifestyles that a cultural group embraces.

No culture exists in isolation. ${ }^{4}$ Modern day communication and intercontinental travel has made different populations to interact constantly thereby bringing a cultural evolution with constant changes in dietary lifestyle and even their reproductive choices. Majority of Asian women in Asia embrace menopause with acceptance, treating it as another milestone in the path of life. Hence, most Asian women look upon the problems that accompany the onset of menopause as an inevitable part of aging that needs to be embraced rather than struggled against. ${ }^{15}$ It is also important to understand that attitudes and beliefs can be modified by education. Women of higher educational levels are more willing to accept that there may be medical conditions associated with the menopause that require medical attention. Conversely, women of lower educational levels are more inclined to believe that menopause is a completely natural event for which there is no need to seek any medical attention.

The SWAN study ${ }^{11}$ showed that Asian women living in the United States viewed menopause less positively than their Western counterparts. This is probably an effect of acculturation.

\section{BIOLOGICAL DIFFERENCE}

Can different menopausal experiences of women of different ethnic groups be solely because of their cultural differences or is there a difference in physiology also? There are differences in the endocrine changes during mid life among different ethnic groups. The SWAN study found that Chinese and Japanese have lower estradiol levels during their mid life transition as compared to Caucasian and AfricanAmerican women. However, it also showed that follicles stimulating hormone (FSH) levels between these two groups of populations. ${ }^{12,13}$ 


\section{SEXUALITY AND THE ASIAN MENOPAUSAL WOMEN}

Asian women are thought to have a more conservative attitude toward sexuality than their Western counterparts. Menopause does have a negative impact on the level of sexual activity; women in higher income and of higher educational levels are more likely to be sexually active.

The changes that accompany menopause, such as vaginal dryness and loss of sexual desire are common in both Western and Asian women. ${ }^{18}$ However, Asian women tend to regard these changes as less important. A large proportion of these women are unlikely to be disturbed by these changes. One survey, was conducted by a pharmaceutical company in seven European countries (4,200 women) and five Asian countries (1,000 women). ${ }^{19}$ Sixty-four percent of Asian women did not feel that their reduced sexual desire lowered their self confidence and more than $90 \%$ accepted it as a natural consequence of getting old. ${ }^{8,14}$

\section{ASIAN WOMEN'S RESPONSE TO MENOPAUSAL SYMPTOMS}

Hormone therapy (HT) is not a popular option. ${ }^{10}$ Herbal and traditional therapies are popular options. It is pertinent to highlight that the most common symptom in many Asian populations is body ache and shoulder stiffness. ${ }^{16}$ Aside from cultural and economic reasons, HT is not effective against body aches and shoulder stiffness and hence use of it is not high in Asian countries.

\section{THE FUTURE OF MENOPAUSE MANAGEMENT IN ASIAN WOMEN}

The current trend of HT use is 'individualization of treatment'. ${ }^{17}$ One basic and important consideration is the dosage. Asian women have lower body mass indices and are of smaller build. The metabolism may be quite different from the Western women.

Asian women have a rather different risk profile from the Western women. ${ }^{14}$ Asian women have a lower risk of deep vein thrombosis ${ }^{19}$ and the risk of thrombosis from HT may be lower. From information that we have, the herbal alternatives were more like placebo although use of soya and black co hash did demonstrate and did bring about an improvement in hot flushes. ${ }^{21,22}$ There is so much in these traditional treatments that we need to know. Well designed trials should be conducted in order to demonstrate the efficacy and the safety of these herbal medicines. ${ }^{23}$ Asian women have different health risk benefit of HT. ${ }^{20}$ It is important to adopt a management option of menopause which are culturally acceptable.

\section{REFERENCES}

1. Loh FH, Khin LW, Saw SM, Lee JJ, Gu K. The age of menopause and the menopause transition in a multiracial population: a nation-wide Singapore study. Maturitas 2005;52:169-180.

2. Melby MK, Lock M, Kaufert P. Culture and symptom reporting at menopause. Hum Reprod Update 2005;11:495-512.

3. Ho SC, Chan SG, Yip YB, Cheng A, Yi Q, Chan C. Menopausal symptoms and symptom clustering in Chinese women. Maturitas 1999;33:219-227.

4. Boulet MJ, Oddens BJ, Lehert P, Vemer HM, Visser A. Climacteric and menopause in seven South-east Asian countries. Maturitas 1994;193:157-176.

5. Porter M, Penny GC, Russell D, Russell E, Templeton A. A population based survey of women's experience of the menopause. Br J Obstet Gynaecol 1996;103:1025-1028.

6. Freeman EW, Sammel MD, Grisso JA, Battistini M, GarciaEspagna B, Hollander L. Hot flashes in the late reproductive years: risk factors for African American and Caucasian women. J Womens Health Gend Based Med 2001;10:67-76.

7. Gold EB, Block G, Crawford S, et al. Lifestyle and demographic factors in relation to vasomotor symptoms: baseline results from the Study of Women's Health Across the Nation. Am J Epidemiol 2004;159:1189-1199.

8. Shea JL. Parsing the ageing Asian woman: symptom results from the China study of midlife women. Maturitas 2006;55: 36-50.

9. Zhao G, Wang L, Yan R, Dennerstein L. Menopausal symptoms: experience of Chinese women. Climacteric 2000;3:135-144.

10. Kimira M, Arai Y, Shimoi K, Watanabe S. Japanese intake of flavonoids and is flavonoids from foods. J Epidemiol 1998;8:168-175.

11. Sommer B, Avis N, Meyer P, et al. Attitudes toward menopause and aging across ethnic/racial groups. Psychosomatic Med 1999;61:868-875.

12. Randolph JF Jr, Sowers M, Bondarenko IV, Harlow SD, Luborsky JL, Little RJ. Change in estradiol and follicle-stimulating hormone across the early menopausal transition: effect of ethnicity and age. J Clin Endocrinol Metab 2004;89:1555-1561.

13. Randolph JF Jr, Sowers M, Bonderenko IV, et al. The relationship of longitudinal change in reproductive hormones and vasomotor symptoms during the menopausal transition. J Clin Endocrinol Metab 2005;90:6106-6112.

14. European and Asian Menopause and Sexual Well-Being Survey commissioned by Organon, 2005/2006 (Unpublished).

15. Aso T. The report of Japanese Nurses Health Study. Presented at: 3rd Asia-Pacific Menopause Federation Scientific Meeting; March 2, 2007; Taipei, Taiwan.

16. Loh FH, Chen LH, Yu SL, Jorgensen LN. The efficacy of two dosages of a continuous combined hormone replacement regimen. Maturitas 2002;41:123-131.

17. Archer DF, Dorin M, Lewis V, Schneider DL, Pickar JH. Effects of lower doses of conjugated equine estrogens and medroxyprogesterone acetate on endometrial bleeding. Fertil Steril 2001;75:1080-1087.

18. Haines CJ, Xing SM, Park KH, Holinka CF, Ausmanas MK. Prevalence of menopausal symptoms in different ethnic groups of Asian women and responsiveness to therapy with three doses 
of conjugated estrogens/medroxyprogesterone acetate: the PanAsia menopause (PAM) study. Maturitas 2005;52:264-276.

19. White RH, Zhou H, Romano PS. Incidence of idiopathic deep venous thrombosis and secondary thromboembolism among ethnic groups in California. Ann Intern Med 1998;128: 737-740.

20. Kung AW, Chao HT, Huang KE, Need AG, Taechakraichana N, Lo FH, et al. Efficacy and safety of raloxifene 60 milligrams/ day in postmenopausal Asian women. J Clin Endocrinol Metab 2003;88:3130-3136.
21. Kronenberg F, Fugh-Berman A. Complementary and alternative medicine for menopausal symptoms: a review of randomized controlled trials. Ann Intern Med 2002;137:805-813.

22. Pockaj BA, Gallagher JG, Loprinzi CL, Stella PJ, Barton DL, Sloan JA, et al. Phase III double-blind, randomized, placebo-controlled crossover trial of black cohosh in the management of hot flashes: NCCTG Trial N01CC1. J Clin Oncol 2006;24:2836-2841.

23. Lewis JE, Nickell LA, Thompson LU, Szalai JP, Kiss A, Hilditch JR. A randomized controlled trial of the effect of dietary soy and flaxseed muffins on quality of life and hot flashes during menopause. Menopause 2006;13:631-642. 